\section{Visual illusion and figural aftereffect in relation to field dependence}

\author{
WILLIAM BYTH* and LESLEY PEARN \\ University of Aberdeen, Aberdeen, Scotland
}

Immergluck has demonstrated that field-independent Ss show larger FAE and smaller illusions than field-dependent Ss. Some criticisms of these findings and Immergluck's replies are discussed. It is suggested that the frequency measures of FAE employed by these studies are particularly prone to nonvisual response effects. An experiment is reported in which magnitudes of illusion and FAE size effects are found to be inversely related to each other but not related to field dependence. The field-dependence relationship described by Immergluck may be predominantly a response effect rather than a perceptual effect.

Recent experiments by Immergluck (1966a, b, c, 1968á, 1970) have presented evidence for a relationship between field dependence (FD)/independence (FID), as measured by a rod-and-frame test (RFT) and visual illusions and visual figural aftereffects (VFAE). FID Ss exhibit more potent FAEs and smaller illusions than do FD Ss. Immergluck's position and findings have been criticized by Pressey \& Koffman (1968), Pressey (1968), and Dodwell (1969) and defended by Immergluck $(1968 b, 1970)$.

These criticisms are based on the possible effect of uncontrolled sex differences. Women are known to be more field dependent than men, and this raises the possibility that they are disproportionately represented at the FD end of the continuum in Immergluck's sample of Ss. It has also been suggested that women may show smaller FAEs than men. Hence, it is possible that the finding of a relationship between FD and FAE is an artifact mediated by sex differences on both measures.

Immergluck has answered these criticisms very adequately in his 1970 paper, showing that FD measures rather than sex relate to "aftereffect potency." By a neat inversion of the argument, he points out that, in randomly selected groups, FD differences could account for reported sex differences.

The further implication of the criticisms is perhaps a more serious one and reflects a general unease about the effects of suggestion on FAE measures. Immergluck himself stresses that the VFAE is "possibly one of the most volatile and difficult to assess perceptual phenomena, with many often very subtle factors determining its course [1968b]." This raises a

*Present address and address for reprints: Department of Psychology, The Queen's University of Belfast, Belfast, Northerm Ireland. serious question concerning the methodologies of all the experiments quoted above. This is not a question of adequacy of controls or of the care and precision of the various Es. It concerns the nature of the data obtained from the $S s$ and the Ss' task.

In Immergluck's experiments, the FAE is measured by presenting $S$ s with two identical test figure (TF) squares and requiring $S$ to respond "equal" or "unequal." The FAE data are thus frequency of "unequal" responses within each group of Ss. Similar data where again frequency of occurrence within the group is what is recorded. In the Pressey and the Pressey and Koffman experiments, the FAE data are again basically frequency data. Their Ss were tested on five sets of patterns, and they responded to physically identical TF figures with judgments which corresponded to "right larger," "left larger," or "equal." Ss were also required to rate the vividness of their experience on a 5-point scale from "just noticeable" to "extremely vivid." Two scores were obtained for each $S$. One was the frequency of occurrence of FAE, and the other was the sum of the five vividness ratings.

None of these experiments provide data on the magnitude of the FAEs, and all use the same type of measure, basically "yes I see it-no I don't." These are precisely the conditions under which we would expect "very subtle factors" such as set and suggestion to have their greatest effect on S's behavior. This expectation is supported by Pressey (1970), who reported significant sex differences in VFAE when the technique outlined above was used but could find no significant sex difference when an adjustment technique was used. Despite the manifest objections to using adjustment techniques in measuring a fast-decaying phenomenon like the VFAE, they do provide magnitude data. Pressey observed that his data raised but did are obtained from illusion situations, not answer the question of whether observed sex differences reflected a true perceptual difference or signified a response bias. An experiment by Byth (in preparation) showed no significant sex difference in magnitude of VFAE, measured by the technique outlined below, but did find that women were significantly more ariable than men, when a coefficient of variability was calculated for each S. This latter finding clearly points to a difference in response behavior rather than a true perceptual difference.

The purpose of the present experiment is to investigate the relationship between FD/FID and magnitude of size effect in illusion and VFAE, with equal numbers of male and female $S s$ in each group. Concentric circles are used as IF (inspection figure)-TF figures in both illusion (Delboef) and FAE (Usnadze) presentation to facilitate comparison of data from the two conditions.

\section{SUBJECTS}

The Ss were drawn from the introductory psychology class at the University of Aberdeen. Scores on the group version of Short Form 1 of the Embedded Figures Test (EFT) were obtained for 203 men and 162 women. This form of the EFT contains color and a memory component and consists of 12 items from the Witkin's EFT, with a 10-min time limit on the complete test (Jackson, Messick, \& Myers, 1964). Since no normative data are available for this form of the EFT, Table 1 is included to show the distribution of scores for this group. The FID end of the distribution was extended by noting whether Ss who had all 12 items correct had finished by $5,7,8$, 9 , or $10 \mathrm{~min}$. The obtained distribution is very similar in shape to those reported by Pressey (1968) and Vaught $(1968,1970)$ for the portable RFT, showing the same strong skew towards the FID end of scale, with more men at the FID end and more women at the $F D$ end.

Five male and five female $S s$ were allocated to each of the two groups (FD and FID). All Ss in the FID group scored 12 correct items on the EFT. Four of the women and two of the men completed the test in $5 \mathrm{~min}$, and one woman and three men completed the test in $7 \mathrm{~min}$. In the FD group, the scores for men were $5,4,4,2,0$, and for women, $3,2,2,2,0$.

Subjects were naive with respect to FAE.

\section{APPARATUS}

The stimuli were presented in a Scientific Prototype GB three-channel tachistoscope. The brightness of the ground in all three channels was $17.8 \mathrm{fL}\left(60.98 \mathrm{cdm}^{2}\right)$. The IF circle 
Table 1

Frequency Distribution of Scores on the Form 1 Group EFT* for 162 Male and 203 Female Undergraduates

\begin{tabular}{|c|c|c|c|c|c|c|}
\hline \multirow{3}{*}{\multicolumn{2}{|c|}{ EFT Scores }} & \multicolumn{5}{|c|}{ Percent of Cases } \\
\hline & & \multicolumn{2}{|c|}{ By Sex } & \multicolumn{2}{|c|}{ Within Sex } & \multirow[b]{2}{*}{ Total } \\
\hline & & Male & Female & Male & Female & \\
\hline \multirow{5}{*}{\multicolumn{2}{|c|}{$\begin{array}{l}12 \text { in } 5 \mathrm{~min} \\
12 \text { in } 7 \mathrm{~min} \\
12 \text { in } 8 \mathrm{~min} \\
12 \text { in } 9 \mathrm{~min} \\
12 \text { in } 10 \mathrm{~min}\end{array}$}} & 1.00 & 1.37 & 2.47 & 2.46 & 2.37 \\
\hline & & 3.01 & 1.64 & 6.79 & 2.96 & 4.65 \\
\hline & & 1.92 & 1.10 & 4.32 & 1.97 & 3.02 \\
\hline & & 1.92 & 2.47 & 4.32 & 4.43 & 4.39 \\
\hline & & 1.92 & 3.01 & 4.32 & 5.42 & 4.93 \\
\hline \multirow{12}{*}{ Total } & $\begin{array}{l}12 \\
11\end{array}$ & $\begin{array}{l}9.86 \\
9.32\end{array}$ & $\begin{array}{l}9.59 \\
9.32\end{array}$ & 22.22 & 17.24 & 19.45 \\
\hline & 10 & 6.30 & 10.41 & 14.20 & $\begin{array}{l}10.15 \\
18.72\end{array}$ & $\begin{array}{l}18.04 \\
16.71\end{array}$ \\
\hline & 9 & 4.93 & 4.38 & 11.11 & 7.88 & 9.31 \\
\hline & 8 & 3.56 & 4.38 & 8.02 & 7.88 & 7.94 \\
\hline & 7 & 3.29 & 4.11 & 7.41 & 7.39 & 7.40 \\
\hline & 6 & 2.19 & 3.56 & 4.94 & 6.40 & 5.75 \\
\hline & 5 & 2.19 & 3.56 & 4.94 & 6.40 & 5.75 \\
\hline & 4 & 1.64 & 2.19 & 3.78 & 3.94 & 3.83 \\
\hline & 3 & 0.27 & 2.19 & 0.62 & 3.94 & 2.46 \\
\hline & 2 & 0.27 & 1.37 & 0.62 & 2.46 & 1.64 \\
\hline & 1 & 0.00 & 0.27 & 0.00 & 0.49 & 0.27 \\
\hline & 0 & 0.27 & 0.27 & 0.62 & 0.49 & 0.54 \\
\hline
\end{tabular}

*Twelve items, color, and memory; score is number correct in $10 \mathrm{~min}$

was $45 \mathrm{~mm}$ ( $2 \mathrm{deg} 6 \mathrm{~min}$ ) i.d., placed $32.5 \mathrm{~mm}$ to the left of the central fixation point (FP). The constant TF circle was concentric with the locus of IF and $30 \mathrm{~mm}$ (1 deg $26 \mathrm{~min}$ ) o.d., giving an IF-TF size ratio of 1.5 . Interfigural distance was $7.5 \mathrm{~mm}$ giving $21 \mathrm{~min}$ at the point nearest $\mathrm{FP}$ and $19 \mathrm{~min}$ at the point furthest from FP. The range of the variable comparison figure (CF), equistant from $F P$ at the opposite side from the constant $T F$, was from $20 \mathrm{~mm}$ to $40 \mathrm{~mm}$ in diam, in steps of $1 \mathrm{~mm}$ in diam. One step was approximately a 3-min change in diam.

Stimuli were drawn as fine black lines on white matte cards. For the FAE condition, IF was drawn on one card presented in Channel 1 , and a set of $T F$ cards, each carrying the constant $T F$ and one of the variable CF circles, was presented in Channel 2. For the illusion condition, a set of cards, each carrying the concentric IF and constant $T F$ circles and one of the variable CF circles, was presented in Channel 1. A similar white card, carrying only a central FP, was placed in the blank channel.

\section{PROCEDURE}

The Ss were told that the experiment was concerned with their ability to discriminate between the size of circles presented in pairs under different conditions. They were required to judge whether the constant TF circle ("left") or variable CF circle ("right") was the larger. Judgments of "equal" were not allowed.

Because of the impossibility of obtaining large numbers of judgments from $S s$ in these conditions, the experiment utilized the "up-and-down" method outlined by
Dixon \& Mood (1948), as suggested by Adam (1966), for repeated measures from individual Ss. Briefly, the variable stimulus size changes one step every trial, the direction depending on S's response on the previous trial. Fifty trials were made in each condition, following the first change of judgment by the $S$.

Three conditions were used, namely, control, illusion, and FAE. In the control condition, only the TF cards were presented, for 250 msec. In the illusion condition, the combined IF-TF cards were presented for $500 \mathrm{msec}$, and in the FAE condition, the IF card was presented for $500 \mathrm{msec}$, followed by an ISI of $100 \mathrm{msec}$ and then TF for $250 \mathrm{msec}$. The order of the three conditions was randomized for each $\mathrm{S}$.

\section{RESULTS}

The method used gives a PSE and a measure of $S D$ for each $S$ for each condition. Size effect scores in millimeters were calculated for each $S$ by subtracting the condition PSE from the control PSE. Size effect scores were also expressed as a percentage of control PSE. A variance score was calculated for each $S$ on each condition by expressing $\mathrm{SD}$ as a percentage of PSE.

The mean size effect scores were $+1.67 \mathrm{~mm}(\mathrm{SD}=1.08)$ for the illusion condition and $-1.75 \mathrm{~mm}(\mathrm{SD}=1.03)$ for the FAE condition. The PSEs for both experimental conditions were significantly different from the control PSEs at beyond the 0.01 level.

Analysis of variance showed no significant effect of FD or sex. The within-S condition effect was significant at beyond the $0.001 \%$ level. The correlation between the absolute magnitudes of illusion and FAE scores was $r=-0.606$, which is significantly different from zero at better than the 0.01 level with $\mathrm{df}=18$.

The analysis was repeated with percentage scores, and the same outcome was obtained.

Analysis of the variance scores showed no significant effect of FD or sex. The within-S conditions effect was significant at better than the 0.005 level. Further analysis showed that both the illusion and FAE conditions were significantly more variable than the control condition but were not significantly different from each other.

\section{DISCUSSION}

The $5.31 \%$ increase in apparent size of $\mathrm{TF}$ in the illusion condition and the $5.56 \%$ shrinkage in the FAE condition correspond very closely to those reported in the literature with similar conditions, e.g., by Ikeda \& Obonai (1955). We seem to have a valid measure of illusion and FAE.

This experiment has shown clearly the inverse relationship between illusion and FAE reported by Immergluck. Small illusion implies large $\mathrm{FAE}$, and vice versa. What we cannot support is the relationship between illusion and FAE measures and FD.

It has been argued that the methodology employed in the present experiment, giving magnitude measures of FAE and illusion, is less susceptible to effects of suggestion and set, etc., than the frequency methods used in the experiments cited. Certainly the present technique seems to provide a measure of the perceptual process less biased by response effects than a frequency method. This point is argued more fully elsewhere (Byth, in preparation $^{1}$ ). If this is the case, we have established the inverse illusion/FAE relationship as a predominantly perceptual effect. The failure to find any relationship between the magnitude of these effects and FD suggests that the relationship reported by Immergluck may lie in the response rather than in the perception.

\section{REFERENCES}

ADAM, J. The relationship between visual illusions and figural aftereffects. Australian Journal of Psychology, 1966. $18,130-136$.

DIXON, W. J. \& MOOD, A. M A method for obtaining and analyzing sensitivity data. Journal of the American Statistical Association, 1948,43, 109-126.

DODWELL, P, C. Figural after-effects and field dependence: Another ground for scepticism. Psychonomic Science, 1969 14,84 .

IKEDA, H., \& OBONAI, T. Figural aftereffects, retroactive effect, and simultaneous illusion. Japanese Journal of Psychology, 1955, 26, 235-246. 
IMMERGLUCK, L. Visual figural after-effects and field dependence. Psychonomic Science, 1966a, 4, 219-220.

IMMERGLUCK, L. Figural after-effects, rate of "figure-ground" reversal, and field dependence. Psychonomic Science, 1966b. 6, 45-46.

IMMERGLUCK, L, Resistance to an optical illusion, figural after-effects, and field dependence. Psychonomic Science, $1966 c, 6,281-282$.

IMMERGLUCK, L. Individual differences in figural aftereffect potency: Aftereffect trace vs immediate stimulus context as a determiner of perception. Psychonomic Science, 1968a, 10, 203-204.

IMMERGLUCK, L. Comment on "Figural aftereffects, illusions and the dimension of field dependence." Psychonomic Science, $1968 \mathrm{~b}, 11,363$.

IMMERGLUCK, L. Figural aftereffect potency: A function of sex or field-dependence? Psychonomic Science, $1970,18,317-318$.
JACKSON, D. N., MESSICK, S., \& MYERS, C. T. Evaluation of group and individual forms of embedded-figures measures of field-independence. Educational \& Psychological Measurement, 1964, 24. 177-192.

PRESSEY, A. W. A reply to comments on "Figural aftereffects, illusions and the dimension of field dependence." Psychonomic Science, 1968, 11, 364.

PRESSEY. A. W. Sex differences on tests of visual figural aftereffects. Acta Psychologica, 1970, 34, 78-88.

PRESSEY A W \& KOFFMAN, G. Figural aftereffects, illusions and the dimension of field dependence. Psychonomic Science, 1968, 10, 279-280.

VAUGHT, G. Expected scores in the rod and frame test: Fuel for the Immergluck-Pressey fire. Psychonomic Science, $1968,13,248$.

VAUGHT, G. Expected scores on the rod and frame test revisited. Psychonomic Science, $1970,18,111$.
1. Data on the sex difference in variance scores were obtained from 20 male and 20 female naive first-year students. Experimental conditions were identical to those described above, with the addition of a retroactive FAE condition where TF-CF preceded IF by $100 \mathrm{msec}$ ISI. Ss were selected into four groups representing the extreme levels (+ or -1 SD) of $E$ and $N$ on the Eysenck Personality Inventory. Under those conditions, the variance scores for women were significantly higher than those for men, at the .05 level. There was no effect of $E$ or $N$ on variance scores, and none of the interactions was significant. (The relationship between "Extraversion and the visual figural aftereffect with tachistoscopic presentation" is discussed in a paper by the present author accepted for publication by the British Journal of Psy chology.) 